\title{
Highly Efficient Modification of Bacterial Artificial Chromosomes (BACs) Using Novel Shuttle Vectors Containing the R6K $\gamma$ Origin of Replication
}

\author{
Shiaoching Gong, ${ }^{1,2}$ Xiangdong William Yang, ${ }^{1}$ Chenjian Li, ${ }^{1}$ \\ and Nathaniel Heintz ${ }^{1,2,3,4}$ \\ ${ }^{1}$ Laboratory of Molecular Biology, ${ }^{2}$ Gensat project, ${ }^{3}$ Howard Hughes Medical Institute, The Rockefeller University, New York, \\ New York 10021, USA
}

\begin{abstract}
Bacterial artificial chromosome (BAC) mediated transgenesis has proven to be a highly reliable way to obtain accurate transgene expression for in vivo studies of gene expression and function. A rate-limiting step in use of this technology to characterize large numbers of genes has been the process with which BACs can be modified by homologous recombination in Escherichia coli. We report here a highly efficient method for modifying BACs by using a novel set of shuttle vectors that contain the R6K $\gamma$ origin for DNA replication, the $E$. coli RecA gene for recombination, and the $S a c B$ gene for negative selection. These new vectors greatly increased the ease with which one can clone the shuttle vectors, as well as screen for co-integrated and resolved clones. Furthermore, we simplify the shuttle vector cloning to one step by incorporation of a "built-in" resolution cassette for rapid removal of the unwanted vector sequences. This new system has been used to modify a dozen BACs. It is well suited for efficient production of modified BACs for use in a variety of in vivo studies.
\end{abstract}

Bacterial artificial chromosomes (BACs) and P-1 derived artificial chromosomes (PACs) have several advantages over the traditional large DNA cloning system, the yeast artificial chromosomes (YACs). These include large carrying capacity ( 100-300 kb), high clonal stability, low rate of chimerism, and the ease with which they can be handled ( Shizuya et al. 1992; Ioannou et al. 1994; Marra et al. 1997; Kelley et al. 1999). BACs have served as the primary source of archived genomic DNA for a variety of genome mapping and sequencing projects (Mozo et al. 1999; Hoskins et al. 2000; Osoegawa et al. 2000; McPherson et al. 2001). Indeed, physical contigs are now available for the entire human genome and the mouse genome, as well as a variety of other experimental organisms (Mozo et al. 1999; Hoskins et al. 2000; Osoegawa et al. 2000; McPherson et al. 2001).

Transgenic mice are important tools for in vivo genetic studies. The conventional transgenic constructs with $<20 \mathrm{~kb}$ of the genomic sequence often result in strong position effects, leading to lack of expression or incorrect expression. Because the genomic DNA inserts in BACs are sufficiently large in most instances to carry an entire transcription unit and its associated regulatory regions, BACs can be used for a variety of functional studies that could not be accomplished by using conventional transgenic approaches. An important advance in the use of BACs for functional studies came with the development of methods for precise manipulation (i.e., marker/gene insertion, deletion, point mutation, etc.) of the genomic DNA carried in the BAC (Yang et al. 1997). This ability to manipulate BAC constructs made possible strategies for gene expression and function studies, as well as cell mark-

\section{${ }^{4}$ Corresponding author.}

E-MAIL Heintz@rockvax.rockefeller.edu; FAX (212) 327-7878. Article and publication are at http://www.genome.org/cgi/doi/10.1101/ gr.476202. ing and isolation experiments, that had previously been widely used only in invertebrate systems (Heintz 2001).

The first and, so far, most widely used method (Yang et al. 1997) for manipulation of BAC DNA relies on a temperature-sensitive pSV1.RecA shuttle vector carrying the Escherichia coli RecA gene, which restores to the recombinationdeficient BAC host the ability to undergo the homologous recombination steps required to generate precise modifications at a desired position within the genomic DNA insert. This system has been successfully applied to generate a series of murine BAC transgenes with accurate expression of marker genes in vivo, including Zipro1 (Yang et al. 1997, 1999), Calbindin (X.W. Yang, W. Jiang, and N. Heintz, unpubl.), Acha9 (Zuo et al. 1999), Rag1 and Rag2 (Yu et al. 1999a,b), Renin-1 (Mullins et al. 2000), NPY (DeFalco et al. 2001), Myf4/Myf5 (Carvajal et al. 2001), P57 (Kip2) (John et al. 2001a), and Neuronatin (John et al. 2001b). Several other systems for BAC modification protocols have subsequently been developed, by using transient introduction of RecE/T or $\lambda$ Red and Gam genes to achieve proper targeting of the desired modification within the BAC ( Jessen et al. 1998; Zhang et al. 1998; Imam et al. 2000; Lee et al. 2001).

Here we report a novel RecA-based system for BAC modification that is simple, highly efficient, and suitable for largescale studies. This system relies on a new shuttle vector containing an E. coli replication origin (R6k $\gamma)$ that can not replicate in the BAC host strain DH1OB (Filutowicz and Rakowski 1998), a RecA gene to support homologous recombination, and a highly efficient negative selectable marker $(s a c B)$ to enhance the removal of unwanted vector sequences from the manipulated BAC. By using this new BAC modification method, we have prepared BAC transgenic constructs for a dozen central nervous system (CNS) expressed genes. This new BAC modification method can be readily applied for large-scale studies of gene expression and function in vivo. 


\section{RESULTS}

\section{An Improved Shuttle Vector for BAC Modification Based on the R6k $\gamma$ Origin of Replication}

BAC libraries are maintained in the $R e c A^{-}$bacterial strain (DH10B), which is deficient in homologous recombination (Schizuya et al. 1992). The first step in manipulating BACs involves restoration of the competence for homologous recombination by introduction into the host cell of an enzyme or enzymes that can complement its deficiency for homologous recombination, and selection against freely replicating shuttle vector to identify cells in which the shuttle vector had co-integrated into the BAC by homologous recombination. In our original BAC modification system, the temperaturesensitive pSV1.RecA shuttle vector may replicate in the BAC host cells at a low level to generate a background of false positives, which may reduce the co-integration efficiency (defined as the number of correct co-integrates among the total number of colonies tested).

A.

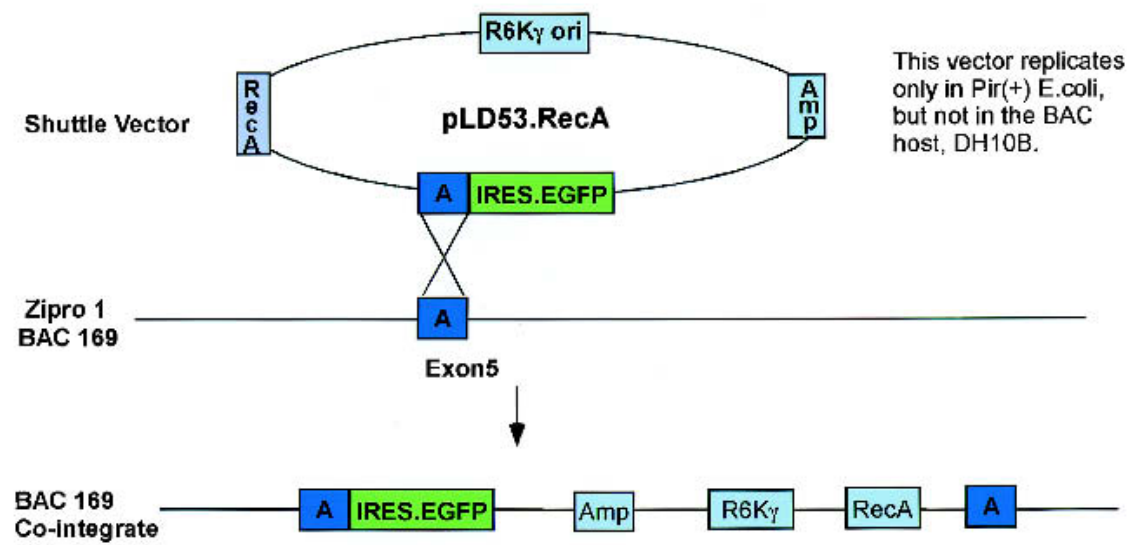

B.

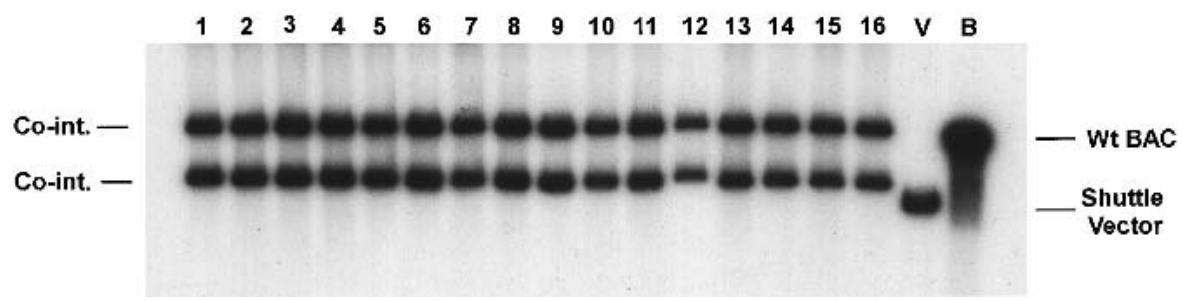

Figure 1 (A) Efficient modification of a Zipro1 BAC by using R6ky RecA-based shuttle vector. A 500-bp fragment corresponding to the last exon of the Zipro 1 gene (Yang et al. 1997) and an IRESEGFP marker gene were cloned into pLD53-RecA vector. This shuttle vector was then electroporated into Zipro1 containing BAC169 cells (Yang et al. 1997). Co-integrates were formed via homologous recombination and selected by chloramphenicol and ampicillin. (B) Southern blot analysis of the cointegrate BAC clones. Co-integrates BAC DNA were digested with Spel and separated by electrophoresis on a $1 \%$ agarose gel. The DNA was transferred to nylon membrane, and the blot was analyzed by using the "A Box" as a probe: co-integrate BAC clones (lanes 1-16), wild-type BAC (lane B), and shuttle vector (lane $V$ ). tested the pLD53 vector described by Metcalf et al. (1996). tor contains an R6k $\gamma$ origin of replication, which is absolutely dependent on the $\pi$ protein encoded by the pir gene for replication (Filutowicz et al. 1998). It can be grown at (he hypothesized that a shuttle vector containcombination between the shuttle vector and the BAC. And the efficiency with which we recovered correct co-integrates could be relatively high because there should be few backround colonies containing free shuttle vectors.

To test this strategy, we constructed a shuttle vector based on pLD53 (Metcalf et al. 1996) that carried the E. coli RecA gene, an IRES.EGFP marker gene, and a 500-bp homology arm "A" corresponding to the last exon of the Zipro1 gene (Yang et al. 1999), as shown in Figure 1 . The vector was electroporated into a Zipro1 containing BAC cells, and the transformants were grown in liquid LB containing chloramphenicol (Chlor) and ampicillin (Amp) overnight. The co-integrates were further selected by two additional rounds of liquid growth in Amp and Chlor before plating on $\mathrm{LB}$ plates containing these selectable markers. DNA was prepared from 16 individual colonies and analyzed for the presence of the correct co-integrates. As illustrated in Figure 1, all 16 independent colonies contain the correct co-integrates, and the co-integration efficiency in this case was $100 \%$. Furthermore, DNA fingerprinting showed no gross rearrangements or deletions in these modified BACs (data not shown). This result demonstrates that the transient expression of $\operatorname{Rec} A$ from a nonreplicating R6k $\gamma$-RecA shuttle vector is sufficient to support homologous recombination in the recombination-deficient BAC host, and that this selection protocol greatly facilitates the identification of the desired co-integrates.

\section{The Use of pLD53.RecA Vectors for the Two-Step BAC Modification}

Our original pSV1.RecA-based BAC modification system uses the two steps of homologous recombina- 
tion-a co-integration step, which results in complete integration of the shuttle vector into the BAC, and a resolution step, which results in excision and subsequent loss of the shuttle vector and precise placement of intended modification in the chosen site on the BAC (Yang et al. 1997). Such a two-step modification protocol is highly desirable for transgenic studies because it results in precise modification of the BAC without leaving any unwanted sequences behind, unlike

\section{A. Two-Step BAC Modification with PLD53 SC-AB Vector}

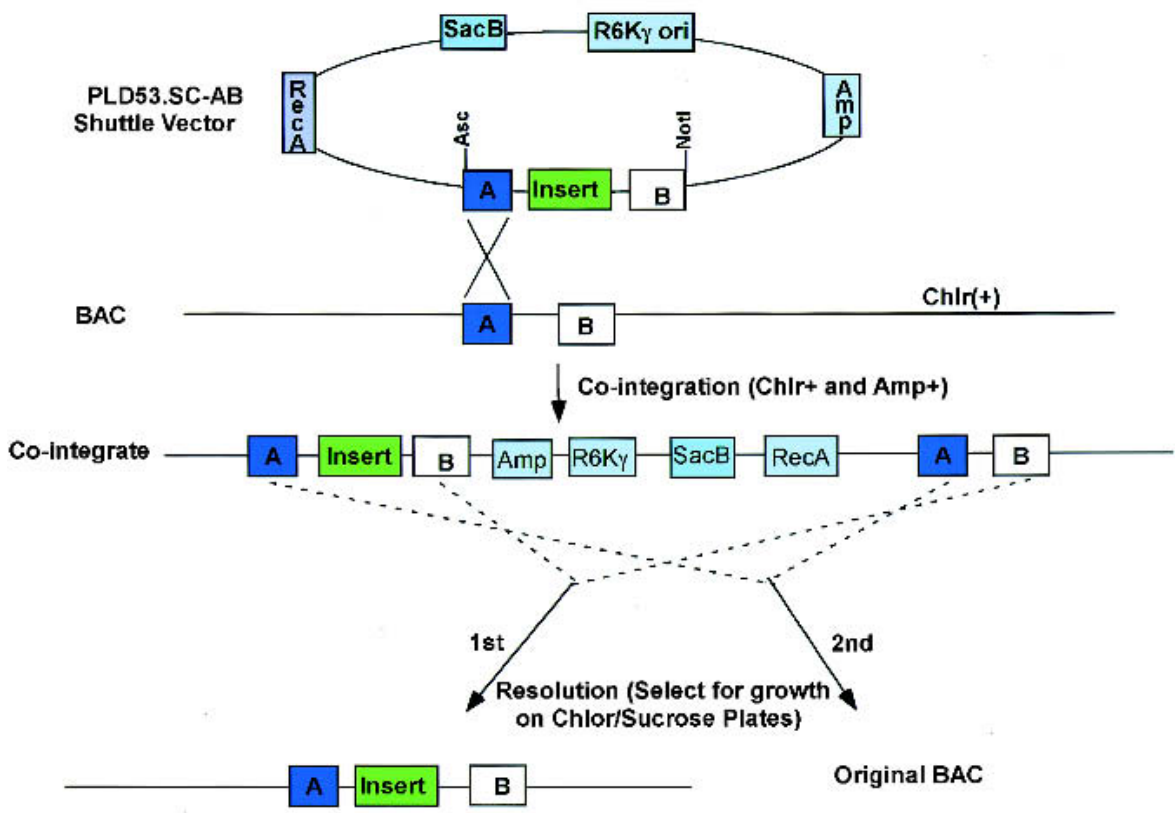

B. Modification of a Huntingtin BAC Using the pLD53.SC-AB Vectors

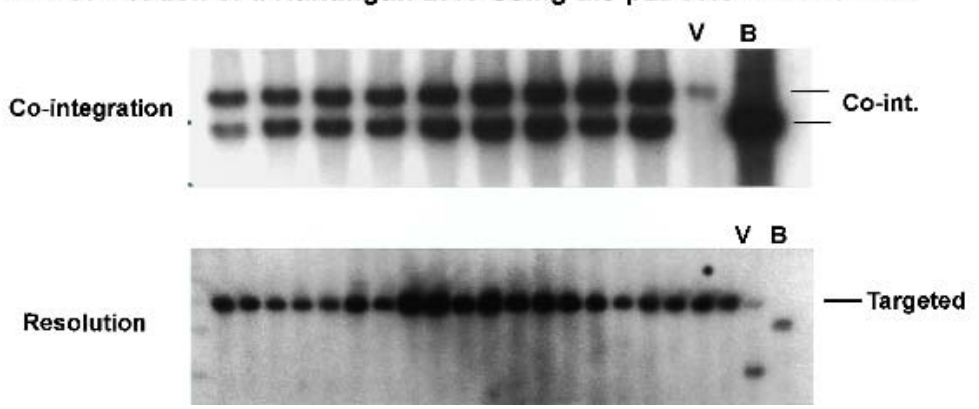

Figure 2 A schematic representation of the two-step BAC modification system with pLD53.SC-AB vector. (A) The pLD53.SC-AB vector is based on the backbone of the plasmid pLD53 (Metcalf et al. 1996). A Sall-Notl fragment containing a SacB gene and a RecA gene was subcloned into the pLD53 vector. This shuttle vector carries a R6ky origin, an ampicillin-resistant gene, and Ascl and Notl sites as unique cloning sites for subcloning the recombination cassette, which contains a modification (insertion, deletion, or point mutation) flanked by two homology arms of $\sim 500 \mathrm{bp}$ each. The two BAC modification steps are illustrated: (1) The co-integration of the shuttle vector pLD53.SC-AB into the $B A C$ via homologous recombination through Box A; and (2) the resolution of the co-integrant involves a second homologous recombination event (either through two homology $A$ or two homology $B$ ) to eliminate the pLD53 vector and other unnecessary sequences from the co-integrate. The resolved BACs were selected by growth on sucrose owing to the loss of $\operatorname{SaCB}$ gene. (B) Southern blot analysis of a Huntington BAC clone modified by two-step BAC modification method. Co-integrates and resolved BAC candidates were first screened by PCR (data not shown). Positive clones were selected, and their DNA was digested with EcoRI, separated by electrophoresis on a $1 \%$ agarose gel, and transferred to nylon membrane. The blots were analyzed using the "A Box" as probes. Controls used were wild-type BAC DNA (B) and shuttle vector (V). the RecET- or $\lambda$ Red-based modification protocols in which at extra LoxP site or an extra FRT site is left behind in the inase in further genetic manipulations of these BAC trans-

In order to perform the two-step BAC modification, we $-A B$ shuttle vector (Fig. 2A). Besides the $R 6 K \gamma$ origin, the E. coli RecA gene, and Amp-resistant gene, it also has two unique cloning sites, AscI and NotI, for the sublconing of the recombination cassette. As in our original protocol, the recombination cassette has two homology arms of $\sim 500$ bp each (termed " $A$ " and "B" homology arms), in between which a modification (i.e., insertion, deletion, point mutation) is to be introduced. The shuttle vector also has $S a c B$ gene as a negative selection gene that can be used to select for resolved BACs. The $S a c B$ gene product, levansucrase, converts sucrose to levan, which is highly toxic to the host cells (Gay et al. 1985). Therefore, bacteria containing the $S a c B$ gene are unable to grow on LB plates containing $5 \%$ to $6 \%$ sucrose and can be selected against using this simple plating step. In the original pSV1.RecA-based method, the Tet gene is used for the negative selection step by growing on fusaric acid plates. In the current study, we found that there are several advantages of the SacB gene over the Tet gene as a negative selection marker gene. First, the preparation of sucrose/Chlor plates (only two chemicals besides LB agar) is much simpler than the preparation of the fusaric acid plates ( $\sim 10$ chemicals). Second, sucrose appears much less toxic to the bacteria than does fusaric acid; therefore, the selected colonies grew much faster on sucrose . Third, in our experience, the efficiency of negative selection with the $S a c B$ is better than that of the fusaric acid when using the pLD53 vector system to modify BACs (data not shown).

The outline for the two-step protocol of BAC modification incorporating these features is diagramed in Figure 2A. In the first step, shuttle vector plasmids carrying the recombination cassette (" $\mathrm{A}$ " homology arm, a modification, and "B" homology arm) were electroporated into the BAC host, and the correct co-integrates were selected 
Table 1. Summary of BAC Modification Efficiency by Using the pLD53.SC-AB and pLD53.SC1 Shuttle Vectors

\begin{tabular}{lcc}
\hline Gene name & $\begin{array}{c}\text { Co-integrate } \\
\text { efficiency }\end{array}$ & $\begin{array}{c}\text { Resolution } \\
\text { efficiency }\end{array}$ \\
\hline Two homology arms (using pLD53.SC-AB vector) & & \\
Ht (BAC866-103Q) & $10 / 20(50 \%)$ & $7 / 26(27 \%)$ \\
Ht (BAC866-260Q) & $9 / 20(45 \%)$ & $17 / 25(85 \%)$ \\
Ht (BAC399-260Q) & $3 / 20(15 \%)$ & $20 / 20(100 \%)$ \\
One homology arm (using pLD53.SC1 vector) & & \\
BF1 & $9 / 12(75 \%)$ & $10 / 20(50 \%)$ \\
Pro-Cadherin & $16 / 17(94 \%)$ & $14 / 17(82 \%)$ \\
Leap1 & $4 / 10(40 \%)$ & $20 / 20(100 \%)$ \\
ROR $\alpha$ & $16 / 16(100 \%)$ & $12 / 14(86 \%)$ \\
ROR & $20 / 20(100 \%)$ & $15 / 17(88 \%)$ \\
Ziprol/Ru49 & $16 / 16(100 \%)$ & $20 / 35(57 \%)$ \\
Smoothen & $19 / 19(100 \%)$ & $7 / 20(35 \%)$ \\
$\alpha$ Synuclein & $11 / 20(55 \%)$ & $9 / 20(45 \%)$ \\
Ht (BAC 866-iEGFP) & $20 / 20(100 \%)$ & $11 / 20(55 \%)$ \\
Ht (BAC 399-iEGFP) & $20 / 20(100 \%)$ & $3 / 40(7.5 \%)$ \\
\hline
\end{tabular}

two obvious advantages. First, provision of this built-in resolution cassette obviates the need to clone separate homology arms " $\mathrm{A}$ " and "B" into the shuttle vector to provide independent sites for the cointegration and resolution steps of the BAC modification protocols. In this case, a simple cloning step involving ligation of a PCR-amplified "A" box into the precut pLD53.SC1 shuttle vector is sufficient to produce the targeting construct. In our hands, this simple cloning step was achieved at $\sim 100 \%$ efficiency (data not shown). Second, because the recombination efficiency positively correlates with the homology length, the desired resolution through the built-in recombination cassettes (in this case two $1.4-\mathrm{kb}$ IRES.EGFP sequences) is much

by growth in Chlor and Amp. The co-integrates, through either A or B homology arms, were identified through simple colony PCR, and the positive clones were confirmed by Southern blot analysis. In the second step, resolved clones were selected by direct plating on LB plates with $6 \%$ sucrose and Chlor. Colonies growing on these plates were tested by colony PCR, and the positive clones were confirmed by Southern blot analysis. The modified BACs were fingerprinted by two or three different restriction digestions and were compared with that of the wild-type BACs to ensure that there was no rearrangement or deletion.

Another optional screening step can be incorporated into the protocol to maximize the recovery of the correctly resolved BACs. Because resolved BACs have lost the shuttle vector carrying the $S a c B, \operatorname{Rec} A$, and $A m p$ genes, higher resolution efficiency can be achieved by adding a screen for the loss of the RecA gene and/or the loss of the Amp gene. The loss of RecA gene confers resistance to UV light (Rupp et al. 1971). Those colonies that are UV sensitive $\left(R e c A^{-}\right)$and/or Amp sensitive are chosen from the master plate for further analysis. This simple added screen improves the recovery of the desired resolved products to $>80 \%$ in the majority of cases.

By using the pLD53 SC-AB plasmid, we have modified two different human BACs containing the 170-kb Huntingtin gene. In three separate modifications, we have inserted two different disease-causing mutations, one encoding 103 glutamine repeats and another encoding 260 glutamine repeats into the Huntingtin BACs. In all cases, the co-integration efficiency was between $15 \%$ and $50 \%$, and the resolution efficiency was between $27 \%$ and $100 \%$ (Table 1; Fig. 2B).

\section{The Use of a "Built-In" Resolution Cassette for Two-Step BAC Modification}

To further simplify the shuttle vector cloning process, we next developed an improved strategy for shuttle vector preparation based on a "built-in" resolution cassette. The logic for this design was that if we provide two copies of the marker gene cassette (i.e., IRES.EGFP or EGFP alone) properly positioned in the shuttle vector, those duplicate copies can be used for highly efficient removal of the vector sequences during the resolution step of BAC modification (Fig. 3). This design has more efficient than that through the " $\mathrm{A}$ " homology arms $(\sim 0.5 \mathrm{~kb})$. The fact that resolution occurs through the same cassette in all constructs ensures uniformly high efficiencies of resolution in nearly all experiments. One consequence of the built-in resolution strategy is that the final resolved product contains a duplicated " $\mathrm{A}$ " homology adjacent to the polyA sequence in the resolved BAC (Fig. 3). We believe such small duplication will not affect the transgene expression, because it is a small endogenous sequence and is not transcribed.

The built-in resolution strategy also results in very high co-integration and resolution efficiency. We have modified six different CNS-expressed genes (BF1, pro-Cadherin, Leap1, $R O R a, R O R b$, Zipro1). As shown in Figure 4 and Table 1, the co-integration efficiency in these experiments was between $40 \%$ to $100 \%$ (average, $84 \%$; median, $94 \%$ ), and the resolution efficiency using the built-in $i E G F P$ marker genes was between $50 \%$ to $100 \%$ efficient (average, $77 \%$; median, $82 \%$ ). In summary, the use of built-in resolution cassette with the PLD53.RecA shuttle vectors has greatly simplified the shuttle vector construction and maintained high co-integration and resolution efficiency.

\section{DISCUSSION}

BACs are important large insert vectors used widely in positional cloning studies (Shizuya et al. 1992; Osoegawa et al. 2000). The ability to modify BACs for transgenic studies enables BACs to be used increasingly in functional studies (Heintz 2001). Although several different methodologies are now available for manipulating BACs by homologous recombination, the current study represents a significant improvement on the simplicity and efficiency of the RecA-based BAC modification system. A major finding of the current study is that the R6k $\gamma$-based shuttle vectors, although they can not replicate in the BAC host bacteria, can express sufficient RecA protein to support efficient co-integration of the shuttle vector.

Several features of the current $\mathrm{R} 6 \mathrm{k} \gamma$ vector-based shuttle vectors enable the significant improvement in the RecA-based BAC modification process. First, these plasmids can readily be manipulated in pir(+) bacteria in terms of cloning and DNA preparation. Second, because the nonintegrated shuttle vec- 
tor plasmids could not replicate at all in the BAC host, they are lost automatically. This obviates the need for temperature shifting in the original modification system. Third, the $S a c B$ gene as a negative selection marker gene also has advantages over the Tet gene: It significantly simplifies the plate preparation step (much fewer ingredients in the sucrose plates than in the fusaric acid plates) and shortens the incubation time from $3 \mathrm{~d}$ to overnight. Fourth, the use of UV and/or Amp selection can further increase the resolution efficiency. Finally, the current system enables one to perform colony PCR to identify with high reliability both the co-integrates or resolved BACs. Such colony PCR with the pSV1.RecA system may produce false positives owing to the low persistence of the free shuttle vectors. Therefore, in the current protocol, no DNA preparation is necessary during the modification process. Overall, the current BAC modification system greatly shortens the total time needed for each modification cycle, and one may be able to modify multiple BACs during each cycle. Our data documented that a single investigator can easily use the built-in resolution cassette system to manipulate up to six different BACs simultaneously in each cycle, and each cycle usually takes $\sim 2$ wk to complete.

A highly efficient method for BAC modification allows one to fully explore the advantage of the BAC system for functional studies in the postgenomic era (Magdaleno et al. 1999; Heintz 2000). It is already clear that preparation of BAC transgenic mice can provide an important complement to other studies of gene expression and function such as gene targeting (Magdaleno et al. 1999; Heintz 2000). With the completion of the human genome project and a variety of other genome projects (Adams et al. 2000; Arabidopsis Genome Initiative 2000; Lander et al 2001; Venter et al. 2001), and the increasing ease of identification of appropriate BACs from the existing databases (Mozo et al. 1999; Hoskins et al. 2000; Osoegawa et al. 2000; McPherson et al. 2001; Tao et al. 2001), we believe that the highly efficient BAC modification system presented here can be applied to in vivo large-scale BAC-based studies of gene expression and function.

\section{METHODS}

\section{Genes Used for BAC Modification}

The accession nos. for genes used for modification are listed below: Zipro1/RU49, U41671; BF1, U36760; Pro-cadherin, NM_007767; Leap1, AF220501; ROR $\alpha$, NM_013646; ROR $\beta$, NM_006914; Smoothen, AF089721; Huntingtin, NM002111; and $\alpha$-synuclein, NM007308. BACs were screened either with a PCR probe from the CITB mouse BAC library or with the RPCI-23 library (purchased from Research Genetics) by using standard protocol. Huntingtin and $\alpha$-synuclein BACs were screened from the RPCI-11 human BAC libraries.

\section{Construction of the Vectors}

The plasmids (pLD53.SC-AB and pLD53 SC1) are derived from the pLD53 (Metcalf et al. 1996). pLD53 was digested with $B a m H I$ and SacI to replace the tetAR and oriT origin with a NotI-SalI-SpeI adaptor. The building vector was based on the pBluescript SK vector (Stratagene). A 2.3-kb Sall-EcoRV fragment containing the $S a c B$ gene from Bacillus subtilis was cloned into SalI and EcoRV sites of the pBS.SK vector. A $1.7-\mathrm{kb}$ $B a m H I$ fragment containing RecA from pSV1.RecA (Yang et al. 1997) was subcloned into BamHI site. For pLD53.SC-AB shuttle vector, this cassette was then cloned into NotI-SalI sites of the modified pLD53 vector. Besides the R6Ky origin, the E. coli RecA gene, a SacB gene, and an Amp-resistant gene, this vector also has two unique cloning sites, AscI and NotI, for the subcloning of the " $\mathrm{A}$ " and "B" homology arms. For pLD53-SC1, besides the $S a c B$ gene and RecA gene, a SpeI fragment of IRESEGFP was further cloned into SpeI site of pBluescript SK, and a second IRESEGFP was cloned into AscI site located upstream of the first IRESEGFP; the $5^{\prime}$ end $A s C$ I site was knocked out. A PGK.poly A fragment with $3^{\prime}$ end AscI-NotISwaI-SmaI multiple cloning site was then cloned into AscI and SmaI sites located upstream of the first IRESEGFP. The whole
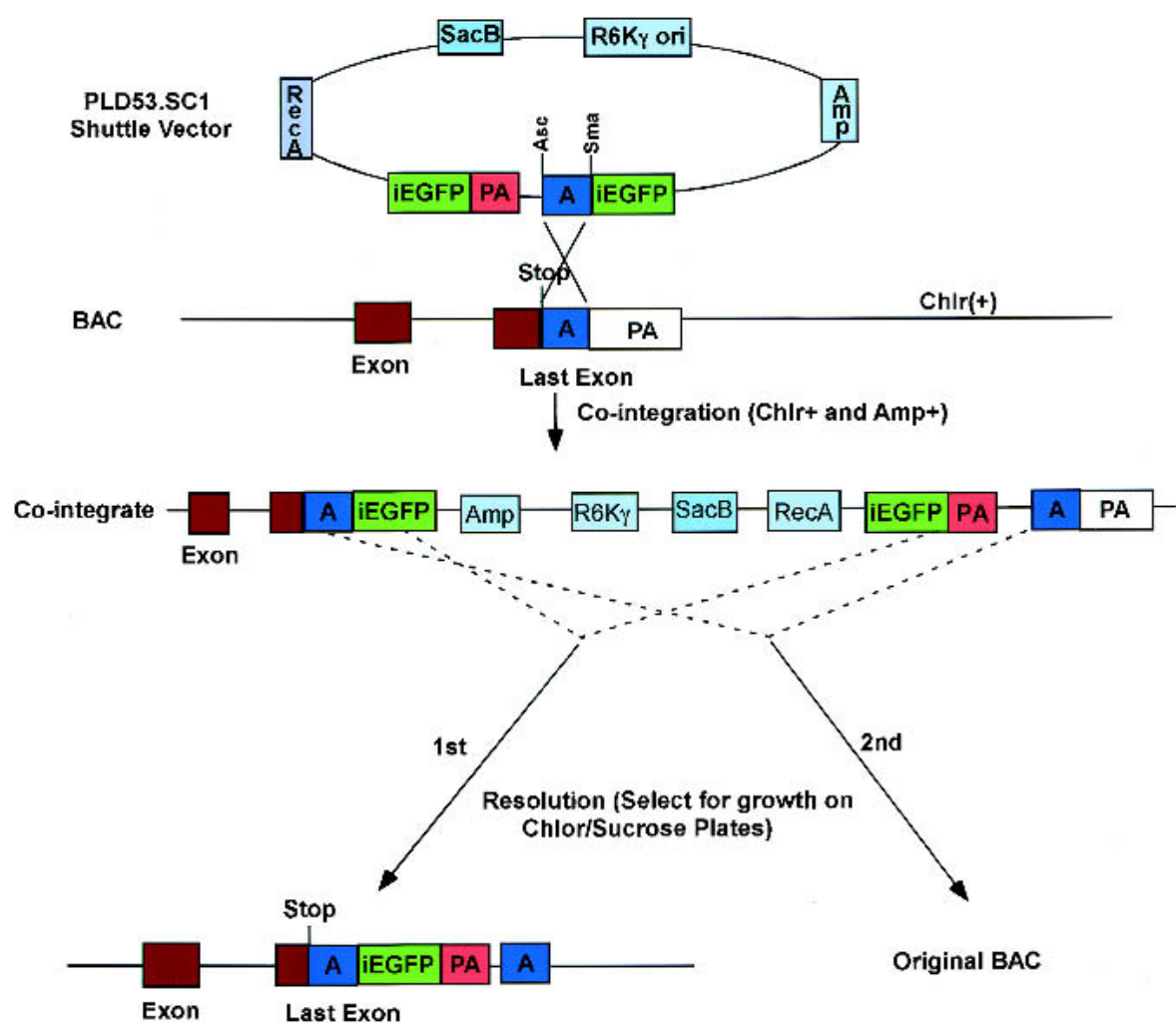

Figure 3 A schematic representation of the two-step BAC modification system with pLD53.SC1 vector. This vector is based on the backbone of the plasmid pLD53 (Metcalf et al. 1996). A Sall-Not1 fragment containing a SacB gene, a RecA gene, two IRESEGFP genes, and multiple cloning sites was subcloned into a mutated pLD53. This shuttle vector carries a R6k $\gamma$ origin, an ampicillin-resistant gene, and Ascl and Smal as unique cloning sites for subcloning of Box A. The two BAC modification steps are illustrated: (1) The co-integration of the shuttle vector pLD53.SC1 into the BAC via homologous recombination through Box A, and (2) the resolution of the co-integrant involves a second homologous recombination event (either through two homology A or two IRESEGFP) to eliminate the pLD53 vector and other unnecessary sequences from the co-integrate. The resolved BACs are selected by growth on sucrose owing to the loss of $S a c B$ gene.

\section{Genome Research} www.genome.org 


\section{Co-integration}

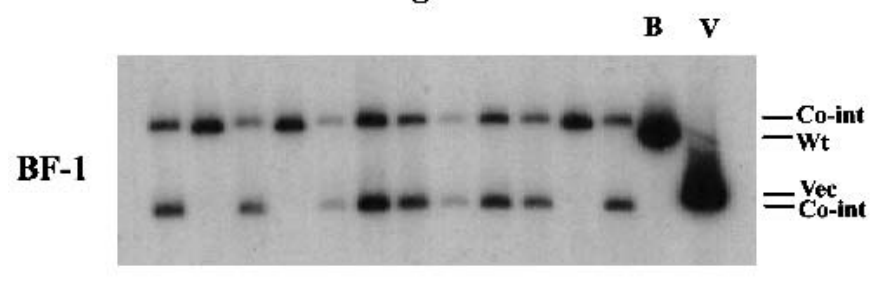

CNR

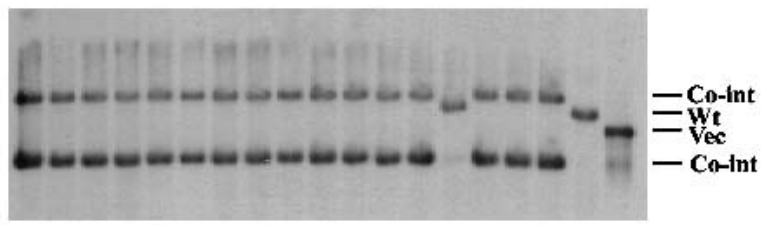

RAR $\alpha$

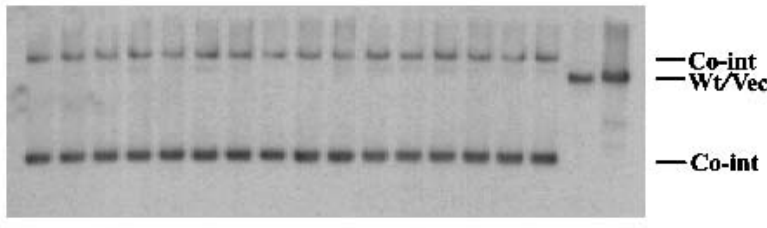

Resolution
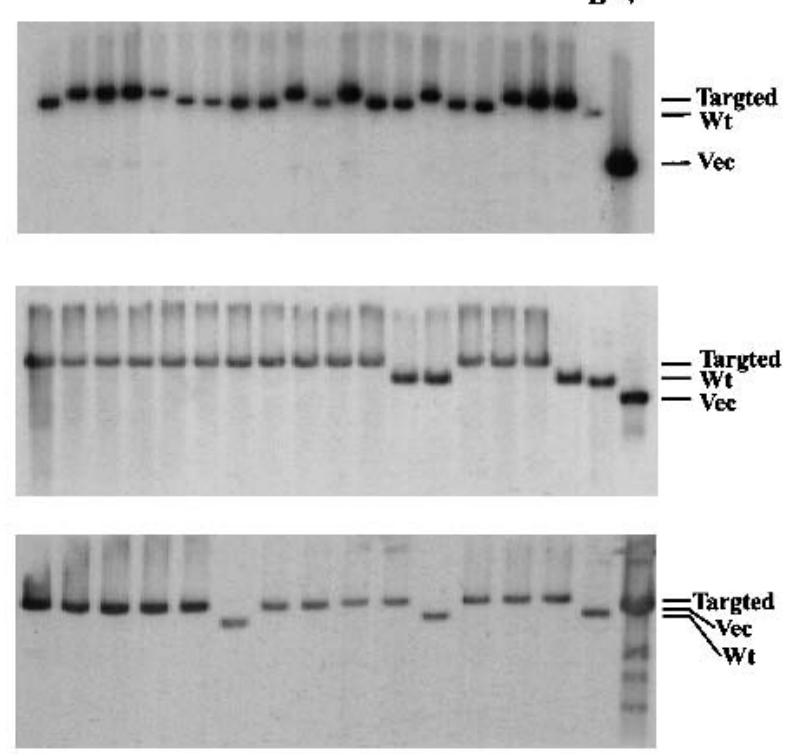

RAR $\beta$

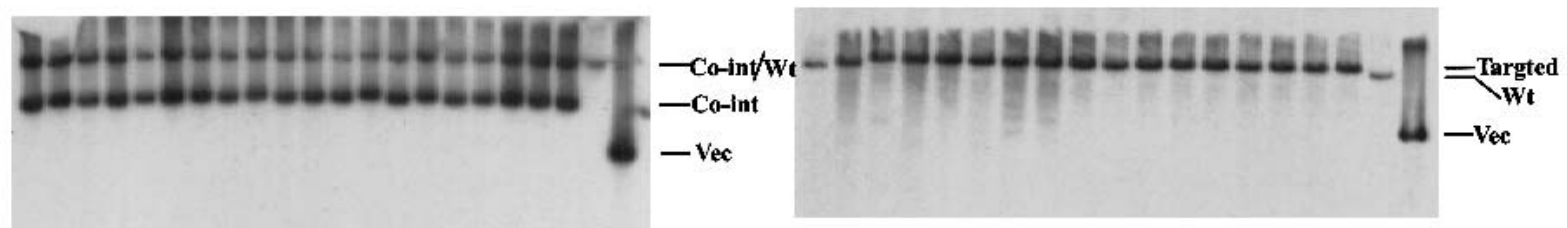

Figure 4 Southern blot analysis of clones modified by the pLD53.SC1 shuttle vector with the built-in resolution strategy. Co-integrates and resolved BAC DNA were digested with Spel, separated by electrophoresis on a $1 \%$ agarose gel, and transferred to nylon membrane. The blots were analyzed using the "A Box" as probes. Controls used were wild-type BAC DNA (lane B) and shuttle vector (lane V).

recombination cassette was then cloned into NotI-SalI sites of the modified pLD53 vector. This shuttle vector was digested with Asc/Sma1 to subclone the 300- to 500-bp "A-box" fragment, which was PCR amplified and digested with AscI before cloning.

\section{Preparation of the Competent Cells for Electroporation and Selection for Co-integrates}

Overnight culture of BAC host bacterial was diluted 1000-fold in $100 \mathrm{~mL}$ of LB medium supplemented with Chlor $(12.5 \mu \mathrm{g} /$ $\mathrm{mL})$, grown to an $\mathrm{OD}_{600}$ of $0.7-0.8$, and chilled on ice for 15 min. Bacteria were collected by centrifugation at $3000 \mathrm{rpm}$ for $10 \mathrm{~min}$ at $4^{\circ} \mathrm{C}$ and resuspended in equal volume of ice-cold $10 \%$ glycerol. This step was repeated twice, and the bacteria pellet was resuspended in $400 \mu \mathrm{L}$ of ice-cold $10 \%$ glycerol. Aliquots were stored in $-80^{\circ} \mathrm{C}$. Before the electroporation, cells were thawed on ice, and $2 \mu \mathrm{L}$ of DNA $(0.5 \mu \mathrm{g} / \mu \mathrm{L})$ was added. Electroporation was performed using BioRad Gene Pulser II and ice-cold cuvettes as follows: $40 \mu \mathrm{L}$ of competent cells were mixed with $2 \mu \mathrm{L}$ of plasmid DNA $(0.5 \mu \mathrm{g} / \mathrm{mL})$ on ice for $1 \mathrm{~min}$. DNA and cells were transferred to a cold $0.1-\mathrm{cm}$ cuvette. Electroporation conditions were $25 \mu \mathrm{F}, 1.8 \mathrm{kV}$, and $200 \Omega$. After electroporation, $1 \mathrm{~mL}$ of SOC was immediately added to the cuvette, and the contents were then transferred to a $17 \times 100$-mm polypropylene tube. After recovery for $1 \mathrm{~h}$ at $37^{\circ} \mathrm{C}$ with shaking, the cells were selected in LB medium containing proper antibiotics for overnight. Then the culture was diluted 1:1000 and incubated for $\sim 14 \mathrm{~h}$ at $37^{\circ} \mathrm{C}$. This culture was further diluted 1:5000 and incubated for $\sim 8 \mathrm{~h}$ at $37^{\circ} \mathrm{C}$. Then, cells were diluted and spread onto LB plates con- taining Chlor $(12.5 \mu \mathrm{g} / \mathrm{mL})$ and Amp $(50 \mu \mathrm{g} / \mathrm{mL})$. Individual colonies were picked to analyze for presence of co-integrates.

\section{Identification and Characterization of Co-integrates and Resolved BACs}

First, the co-integrates were identified by double selection for Chlor $(12.5 \mu \mathrm{g} / \mathrm{mL})$ and Amp $(50 \mu \mathrm{g} / \mathrm{mL})$. Selected colonies were picked, grown in $3 \mathrm{~mL}$ of LB containing Chlor and Amp and were characterized by PCR or Southern blot analysis. DNA was prepared and digested with SpeI. Correct co-integrates were identified by Southern blot by using "A box" as a hybridization probe.

\section{Identification and Characterization of Resolved BACs}

Once the co-integrates were identified, two positive colonies were picked from the Chlor/Amp plates, inoculated with $5 \mathrm{~mL}$ of LB supplemented with Chlor $(12.5 \mu \mathrm{g} / \mathrm{mL})$ and $5 \%-6 \%$ sucrose, and incubated for $8 \mathrm{~h}$ at $37^{\circ} \mathrm{C}$ for CITB-BACs and for 1 $\mathrm{h}$ for RPCI23-BACs. Culture was diluted 1:5000, spread onto LB plates containing Chlor $(12.5 \mu \mathrm{g} / \mathrm{mL})$ and $5 \%-6 \%$ sucrose, and incubated overnight at $37^{\circ} \mathrm{C}$.

To enhance the resolution efficiency, exposure to UV light may be used as a selection step. Colonies were picked and plated on two agar plates: The master plate was incubated at $37^{\circ} \mathrm{C}$ directly; the other plate was exposed with UV light for $30 \mathrm{sec}$ and incubated at $37^{\circ} \mathrm{C}$. UV-sensitive colonies (hence, $\mathrm{RecA}^{-}$) were picked from the master plate and inoculated with $3 \mathrm{~mL}$ of LB supplemented with Chlor $(12.5 \mu \mathrm{g} / \mathrm{mL})$ only. The resolved BACs were screened by PCR or Southern blot. 


\section{ACKNOWLEDGMENTS}

We thank Barry Wanner for kindly providing the pLD53 vector; Hong Zhu, Sanjay Mehta, Cuidong Wong, Tom Sung, Jie Xin, and Wendy Lee for technical assistance; Zhenyu Yue for helpful discussions and critical reading of the manuscript; and Judy Walsh for preparation of the manuscript. S.C. Gong and N. Heintz are supported by NIH grant PHS NO1-NS0233 and PHS NS 39636-03. N. Heintz is also supported by the Howard Hughes Medical Institute. X.W. Yang and C.J. Li are supported by a grant from the Cure Huntington Disease Initiative of the Hereditary Disease Foundation.

The publication costs of this article were defrayed in part by payment of page charges. This article must therefore be hereby marked "advertisement" in accordance with 18 USC section 1734 solely to indicate this fact.

\section{REFERENCES}

Adams, M.D., Celniker, S.E., Holt, R.A., Evans, C.A., Gocayne, J.D., Amanatides, P.G., Scherer, S.E., Li, P.W., Hoskins, R.A., Galle, R.F., et al. 2000. The genome sequence of Drosophila melanogaster. Science 287: 2185-2195.

Arabidopsis Genome Initiative. 2000. Analysis of the genome sequence of the flowering plant Arabidopsis thaliana. Nature 408: 796-815.

Carvajal, J.J., Cox, D., Summerbell, D., and Rigby, P.W. 2001. A BAC transgenic analysis of the Mrf4/Myf5 locus reveals interdigitated elements that control activation and maintenance of gene expression during muscle development. Development 128: $1857-1868$

DeFalco, J., Tomishima, M., Liu, H., Zhao, C., Cai, X., Marth, J.D., Enquist, L., and Friedman, J.M. 2001. Virus-assisted mapping of neural inputs to a feeding center in the hypothalamus. Science 291: $2608-2613$.

Filutowicz, M. and Rakowski, S.A. 1998. Regulatory implications of protein assemblies at the $\gamma$ origin of plasmid R6K: A review. Gene 223: $195-204$.

Gay, P., Le Coq, D., Steinmetz, M., Berkelman, T., and Kado, C.I. 1985. Positive selection procedure for the entrapment of insertion sequence elements in Gram-negative bacteria. $J$. Bacteriol. 164: 918-921.

Heintz N. 2000. Analysis of mammalian central nervous system gene expression and function using bacterial artificial chromosome-mediated transgenesis. Hum. Mol. Genet 9: 937-943.

. 2001. BAC to the future: The use of BAC transgenic mice for neuroscience research. Nat. Rev. Neurosci. 2(12): 861-870.

Hoskins, R.A., Nelson, C.R., Berman, B.P., Laverty, T.R., George, R.A., Ciesiolka, L., Naeemuddin, M., Arenson, A.D., Durbin, J., David, R.G., et al. 2000. A BAC-based physical map of the major autosomes of Drosophila melanogaster. Science 287: 2271-2274.

Imam, A.M., Patrinos, G.P., de Krom, M., Bottardi, S., Janssens, R.J., Katsantoni, E., Wai, A.W., Sherratt, D.J., and Grosveld, F.G. 2000. Modification of human $\beta$-globin locus PAC clones by homologous recombination in Escherichia coli. Nucleic Acids Res. 28: E65.

Ioannou, P.A., Amemiya, C.T., Garnes, J., Kroisel, P.M., Shizuya, H., Chen, C., Batzer M.A., and de Jong, P.J. 1994. A new bacteriophage P1-derived vector for the propagation of large human DNA fragments. Nat. Genet. 6: 84-89.

Jessen, J.R., Meng, A., McFarlane, R.J., Paw, B.H., Zon, L.I., Smith, G.R., and Lin, S. 1998. Modification of bacterial artificial chromosomes through $\chi$-stimulated homologous recombination and its application in zebrafish transgenesis. Proc. Natl. Acad. Sci. 95: $5121-5126$.

John, R.M., Ainscough, J.F., Barton, S.C., and Surani, M.A. 2001a. Distant cis-elements regulate imprinted expression of the mouse p57(Kip2) (Cdkn1c) gene: Implications for the human disorder, Beckwith-Wiedemann syndrome. Hum. Mol. Genet. 10: $1601-1609$.

John, R.M., Aparicio, S.A., Ainscough, J.F., Arney, K.L., Khosla, S., Hawker, K., Hilton, K.J., Barton, S.C., and Surani, M.A. 2001b. Imprinted expression of neuronatin from modified bac transgenes reveals regulation by distinct and distant enhancers. Dev. Biol. 236: 387-399.

Kelley, J.M., Field, C.E., Craven, M.B., Bocskai, D., Kim, U.J., Rounsley, S.D., and Adams, M.D. 1999. High throughput direct end sequencing of BAC clones. Nucleic Acids Res. 27: 1539-1546.

Lander, E.S., Linton, L.M., Birren, B., Nusbaum, C., Zody, M.C., Baldwin, J., Devon, K., Dewar, K., Doyle, M., FitzHugh, W., et al. 2001. Initial sequencing and analysis of the human genome. Nature 409: 860-921.

Lee, E.C., Yu, D., Martinez de Velasco, J., Tessarollo, L., Swing, D.A., Court, D.L., Jenkins, N.A., and Copeland, N.G. 2001. A highly efficient Escherichia coli-based chromosome engineering system adapted for recombinogenic targeting and subcloning of BAC DNA. Genomics 73: 56-65.

Magdaleno, S.M. and Curran, T. 1999. Gene dosage in mice: BAC to the future. Nat. Genet. 22: 319-320.

Marra, M.A., Kucaba, T.A., Dietrich, N.L., Green, E.D., Brownstein B., Wilson, R.K., McDonald, K.M., Hillier, L.W., McPherson, J.D., and Waterston, R.H. 1997. High throughput fingerprint analysis of large-insert clones. Genome Res. 7: 1072-1084.

McPherson, J.D., Marra, M., Hillier, L., Waterston, R.H., Chinwalla, A., Wallis, J., Sekhon, M., Wylie, K., Mardis, E.R., Wilson, R.K., et al. 2001. A physical map of the human genome. Nature 409: 934-941.

Metcalf, W., Jiang, W., Daniels, L.L., Kim, S., Haldimann, A., and Wanner, B.L. 1996. Conditionally replicative and conjugative plasmids carrying lacZa for cloning, mutagenesis, and allele replacement in bacteria. Plasmid 35: 1-13.

Mozo, T., Dewar, K., Dunn, P., Ecker, J.R., Fischer, S., Kloska, S., Lehrach, H., Marra, M., Martienssen, R., Meier-Ewert, S., et al. 1999. A complete BAC-based physical map of the Arabidopsis thaliana genome. Nat. Genet. 22: 271-275.

Mullins, L.J., Payne, C.M., Kotelevtseva, N., Brooker, G., Fleming, S., Harris, S., and Mullins, J.J. 2000. Granulation rescue and developmental marking of juxtaglomerular cells using "piggy-BAC" recombination of the mouse ren locus. J. Biol. Chem. 275: 40378-40384.

Osoegawa, K., Tateno, M., Woon, P.Y., Frengen, E., Mammoser, A.G., Catanese, J.J., Hayashizaki, Y., and de Jong, P.J. 2000. Bacterial artificial chromosome libraries for mouse sequencing and functional analysis. Genome Res. 10: 116-128.

Rupp, W.D., Wilde III, C.E., Reno, D.L., and Howard-Flanders, P. 1971. Exchanges between DNA strands in ultraviolet-irradiated Escherichia coli. J. Mol. Biol. 61: 25-44

Shizuya, H., Birren, B., Kim, U.J., Mancino, V., Slepak, T., Tachiiri, Y., and Simon, M. 1992. Cloning and stable maintenance of 300-kilobase-pair fragments of human DNA in Escherichia coli using an F-factor-based vector. PNAS 89: 8794-8797.

Tao, Q., Chang, Y.L., Wang, J., Chen, H., Islam-Faridi, M.N., Scheuring, C., Wang, B., Stelly, D.M., and Zhang, H.B. 2001 Bacterial artificial chromosome-based physical map of the rice genome constructed by restriction fingerprint analysis. Genetics 158: $1711-1724$.

Venter, J.C., Adams, M.D., Myers, E.W., Li, P.W., Mural, R.J., Sutton, G.G., Smith, H.O., Yandell, M., Evans, C.A., Holt, R.A., et al. 2001. The sequence of the human genome. Science 291: $1304-1351$.

Yang, X.W., Model, P., and Heintz, N. 1997. Homologous recombination based modification in Esherichia coli and germline transmission in transgenic mice of a bacterial artificial chromosome. Nat. Biotech. 15: 859-865.

Yang, X.W., Wynder, C., Doughty, M.L., and Heintz, N. 1999. BAC-mediated gene-dosage analysis reveals a role for Ziprol (Ru49/Zfp38) in progenitor cell proliferation in cerebellum and skin. Nat. Genet. 22: 327-335.

Yu, W., Misulovin, Z., Suh, H., Hardy, R.R., Jankovic, M., Yannoutsos, N., and Nussenzweig, M.C. 1999a. Coordinate regulation of RAG1 and RAG2 by cell type-specific DNA elements 5' of RAG2. Science 285: 1080-1084.

Yu, W., Nagaoka, H., Jankovic, M., Misulovin, Z., Suh, H., Rolink, A., Melchers, F., Meffre, E., and Nussenzweig, M.C. 1999b. Continued RAG expression in late stages of B cell development and no apparent re-induction after immunization. Nature 400: $682-687$.

Zhang, Y., Buchholz, F., Muyrers, J.P.P., and Stewart, A.F. 1998. A new logic for DNA engineering using recombination in Escherichia coli. Nat. Genet. 20: 123-128.

Zuo, J., Treadaway, J., Buckner, T.W., and Fritzsch, B. 1999. Visualization of $\alpha 9$ acetylcholine receptor expression in hair cells of transgenic mice containing a modified bacterial artificial chromosome. Proc. Natl. Acad. Sci. 96: 14100-14105.

Received May 30, 2002; accepted in revised form September 30, 2002. 


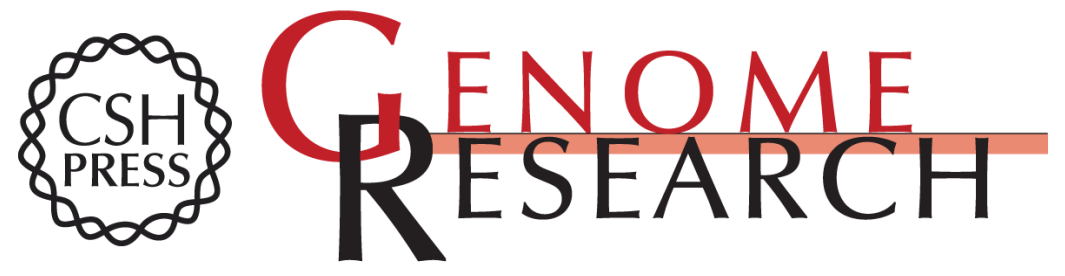

\section{Highly Efficient Modification of Bacterial Artificial Chromosomes (BACs) Using Novel Shuttle Vectors Containing the R6K $\gamma$ Origin of Replication}

Shiaoching Gong, Xiangdong William Yang, Chenjian Li, et al.

Genome Res. 2002 12: 1992-1998

Access the most recent version at doi:10.1101/gr.476202

References This article cites 33 articles, 14 of which can be accessed free at: http://genome.cshlp.org/content/12/12/1992.full.html\#ref-list-1

License

Email Alerting

Receive free email alerts when new articles cite this article - sign up in the box at the Service top right corner of the article or click here.

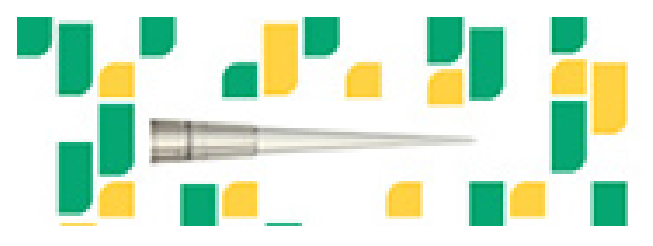

Focused on your science.

To subscribe to Genome Research go to: https://genome.cshlp.org/subscriptions 